\title{
Mice overexpressing growth hormone exhibit increased skeletal muscle myostatin and MuRF1 with attenuation of muscle mass
}

Leslie A. Consitt ${ }^{1,2,3^{*}}$, Alicson Saneda ${ }^{4}$, Gunjan Saxena ${ }^{1}$, Edward O. List ${ }^{3,5}$ and John J. Kopchick ${ }^{1,3,5}$

\begin{abstract}
Background: In contrast to the acute effects of growth hormone $(\mathrm{GH})$ on skeletal muscle protein synthesis, long-term $\mathrm{GH}$ treatment appears to have negligible effects on muscle mass. Despite this knowledge, little is known regarding the chronic effects of $\mathrm{GH}$ on skeletal muscle protein synthesis and atrophy signaling pathways. The purpose of this study was to determine if protein synthesis pathways are attenuated and/or muscle atrophy intracellular signaling pathways are altered in the skeletal muscle of transgenic bovine $\mathrm{GH}(\mathrm{bGH})$ mice.
\end{abstract}

Methods: The gastrocnemius and soleus from 5-month-old male bGH mice $(n=9)$ and wild type (WT) controls $(n=9)$ were harvested and analyzed for proteins involved in the protein synthesis (Akt/mTOR), growth and proliferation (MAPK), and muscle atrophy (MuRF1 and myostatin) pathways.

Results: Total body mass was significantly increased in bGH mice compared to WT controls $(49 \%, P<0.0001)$. When expressed relative to total body mass, the gastrocnemius $(-28 \%, P<0.0001)$, but not the soleus, was significantly lower in mice overexpressing $\mathrm{GH}$, compared to controls. Transgenic bGH mice had elevated phosphorylation levels of protein kinase b (Akt1), 4E-binding protein 1 (4E-BP1), p70 S6 kinase, p42/44, and p38 $(P<0.05)$ compared to WT littermates. Mature myostatin $(26 \mathrm{kDa})$, premature myostatin $(52 \mathrm{kDa})$, and activin receptor type IIB (AcvR2B) protein levels were increased in bGH mice $(P<0.05)$, along with elevated phosphorylation levels of mothers against decapentaplegic homolog (Smad2) (59\%, $P<0.0001)$. Mice overexpressing GH had increased MuRF1 expression $(30 \%, P<0.05)$ and insulin receptor substrate 1 (IRS1) serine phosphorylation $(44 \%, P<0.05)$ in the gastrocnemius, but not the soleus, when compared to controls.

Conclusions: These findings demonstrate that chronic elevations in circulating GH have a critical impact on signaling pathways involved in skeletal muscle protein synthesis and atrophy, and suggest that MuRF1, myostatin, and IRS1 serine phosphorylation may act to inhibit exaggerated glycolytic muscle growth, in environments of chronic GH/IGF-1 excess.

\section{Background}

Skeletal muscle mass is determined by the net balance between intramuscular pathways responsible for protein synthesis and atrophy. The decline in muscle mass is associated with reduced quality of life [1], as

\footnotetext{
*Correspondence: consitt@ohio.edu

'Department of Biomedical Sciences, Ohio University, 228 Irvine Hall, Athens, Ohio 45701, USA

2Ohio Musculoskeletal and Neurological Institute, Ohio University, Athens, Ohio 45701, USA

Full list of author information is available at the end of the article
}

well as, a number of health related conditions including, aging [2], cancer [3], chronic obstructive pulmonary disease (COPD) [4, 5], cystic fibrosis [6], and acquired immune deficiency syndrome (AIDS) [6]. Despite this knowledge, the cellular mechanisms responsible for regulating muscle mass, especially during chronic conditions, remain unclear.

Growth hormone $(\mathrm{GH})$, a protein secreted from the anterior pituitary gland, is an anabolic hormone that plays a critical role in growth [7] and metabolism [8]. While many of the growth promoting properties of $\mathrm{GH}$ 
in skeletal muscle have been attributed to the indirect effects of insulin-like growth factor-1 (IGF-1) [9], acute $\mathrm{GH}$ infusion studies have provided compelling evidence that this hormone also has a direct role in stimulating skeletal muscle protein synthesis [10, 11]. GH binds to its receptor leading to the recruitment and phosphorylation of Janus kinase 2 (JAK2) and its most recognized downstream target, signal transducer and activator of transcription 5 (STAT5) [12, 13]. Similar to IGF-1, GH stimulates the IRS1/Akt [14-16] and mitogen-activated protein kinase (MAPK) [16, 17] pathways which are thought to be the main pathways contributing to GH/IGF1-induced muscle hypertrophy. The activation of Akt1 is a primary event in regulating skeletal muscle development since it controls the phosphorylation of a number of substrates involved in protein synthesis including mechanistic target of rapamycin (mTOR) (and its downstream targets 4E-binding protein 1 (4E-BP1) and p70S6 kinase) and glycogen synthase kinase $3 \beta$ (GSK3 $\beta$ ), as well as, the inhibition of protein degradation via the forkhead transcription factor (FOXO) pathway. The MAPK signaling cascade, especially the $\mathrm{p} 42 / \mathrm{p} 44$ and $\mathrm{p} 38$ pathways, are also known to have an important role in skeletal muscle proliferation and differentiation [18-20].

Declines in circulating GH and IGF-1 often parallel decreases in skeletal muscle mass, making GH supplementation a potentially attractive treatment for conditions of $\mathrm{GH}$ deficiency. However, unlike the short-term effects of $\mathrm{GH}$ on skeletal muscle protein synthesis [21], the majority of research examining the effects of chronic GH exposure have been negligible. For example, increases in skeletal muscle mass were reported to plateau after only 16 weeks of $\mathrm{GH}$ replacement therapy in GH-deficient adults [22] and no gains in skeletal muscle hypertrophy were achieved in healthy, elderly men after 10-12 weeks of GH supplementation $[23,24]$. These findings are further supported by studies using adults with acromegaly, a condition with excess circulating levels of $\mathrm{GH}$ and IGF-I. Patients with active acromegaly experience organomegaly [25]; however, these individuals either have similar skeletal muscle mass as healthy controls [26] or evidence of muscle atrophy, especially in type 2 fibers $[27,28]$.

The lack of muscle hypertrophy during conditions of chronic GH excess suggest the IRS1/Akt and/or MAPK pathways become desensitized, or alternative pathways involved in muscle atrophy become upregulated. Muscle RING factor 1 (MuRF1) and myostatin are two candidates that could play a role in $\mathrm{GH}$-induced muscle atrophy since both are preferentially expressed in type 2 muscle fibers and believed to play a critical role in fast-twitch muscle atrophy [29, 30]. MuRF1 is an E3 ubiquitin ligase, responsible for proteasomal degradation [31], and can act independent of the myostatin pathway to induce muscle atrophy. Myostatin, a member of the transforming growth factor- $\beta$ (TGF- $\beta$ ) superfamily is synthesized in skeletal muscle [32] and promotes muscle wasting through stimulation of its canonical Smad2/3 pathway. In cardiac tissue, myostatin has been suggested to act as a chalone [33, 34], a protein secreted by tissue to provide a negative feedback mechanism to control tissue size [35]. Preliminary research indicates that GH signaling may play a role in regulating myostatin expression [36]; however, no known studies have examined the Smad2/3 pathway in response to $\mathrm{GH}$ excess.

Bovine GH (bGH) mice have frequently been used as a model to study the effects of chronic GH exposure [37-39]. Similar to patients with acromegaly, these mice have increased linear growth [39], decreased body fat $[38,39]$, and are insulin resistant [37, 40, 41]. Of particular interest, organs including the liver, kidney, heart, and lungs experience exaggerated growth in bGH mice even when expressed relative to total body weight [39], whereas relative skeletal muscle mass does not differ from control mice [42]. Further, absolute grip strength has been reported to be similar between mice overexpressing $\mathrm{GH}$ and controls, and decreases in strength have been documented in bGH mice when expressed relative to body weight, suggesting chronic GH excess may produce less efficient muscle [43]. These findings support a tissue-specific negative feedback mechanism in skeletal muscle during conditions of $\mathrm{GH}$ excess. The main objectives of the current study was to (1) determine if key intracellular signaling pathways responsible for protein synthesis are attenuated in the skeletal muscle of bGH mice and (2) determine if MuRF1 and/or the myostatin pathway are upregulated in bGH mice, suggesting these protein act as a skeletal muscle chalone in conditions of chronic GH/ IGF1 exposure.

\section{Methods \\ Animals}

Male bGH transgenic $(n=9)$ and wild type littermate controls $(n=9)$ were generated as previously described $[38,39]$. Briefly, bGH mice were generated by a pronuclear injection into a C57BL/6J embryo with the bGH complementary DNA (cDNA) fused to the mouse metallothionein transcriptional regulatory element. Mice were screened for the bGH gene using polymerase chain reaction (PCR), and bGH males were bred to non-transgenic (NT) females to further propagate the line. Successive generations were bred and screened in a similar manner. Mice were housed 2-4 mice per cage in the temperature-controlled $\left(23{ }^{\circ} \mathrm{C}\right)$ vivarium and exposed to $14-\mathrm{h}$ light/10-h dark cycle. All mice were 
allowed ab libitum access to water and food (ProLab RMH 3000; PMI Nutrition International). At 5 months of age, mice were euthanized by $\mathrm{CO}_{2}$ inhalation and the gastrocnemius and soleus muscles were collected. Mice were fasted for $12 \mathrm{~h}$ prior to euthanasia. All procedures performed with the mice were approved by the Institutional Animal Care and Use Committee at Ohio University and are in accordance with all standards set forth by federal, state, and local authorities.

\section{Western blot procedure}

Skeletal muscle was homogenized, and protein content was determined as previously described [44, 45]. Muscle lysate $(20-30 \mu \mathrm{g}$ cellular protein) was separated by sodium dodecyl sulfate polyacrylamide gel electrophoresis (SDS-PAGE), electrotransferred onto polyvinylidene difluoride membranes (Millipore, Billerica, MA) and probed overnight with Cell Signaling (Beverly, MA) antibodies for JAK2 (Tyr1007/1008), JAK2 total, STAT5 (Tyr694), STAT5 total, Akt1 (Ser473), Akt2 (Ser474), Akt1 total, Akt2 total, AS160 (Ser588), AS160 (Ser666), AS160 total, TBC1D1 (Thr590), TBC1D1 (Ser700), TBC1D1 total, insulin receptor $\beta$, IRS1 (Ser307), mTOR (Ser2448), mTOR total, p70 S6 kinase (Thr389), p70 S6 kinase total, 4E-BP1 (Thr37/46), 4E-BP1 total, p38 (Thr180/Tyr182), p38 total, p44/42 (Thr202/Tyr204), p44/42 total, JNK (Thr183/Tyr185), JNK total, GSK-3 $\beta$ (Ser9), GSK3 $\alpha / \beta$ total, Fox01 (Thr24)/Fox03a (Thr32), FOXO1 total, glyceraldehyde 3-phosphate dehydrogenase (GAPDH), Santa Cruz Biotechnology (Santa Cruz, CA) antibodies for IRS1 total, myostatin, and muscle RING factor 1 (MuRF1), Developmental Studies Hybridoma Bank (University of Iowa) antibodies for myosin heavy chain (MHC) I and MHC IIb, as well as, an Abcam (Cambridge, MA) antibody for Activin Receptor Type IIB. Proteins were visualized by horseradish peroxidase-conjugated IgG antibodies (Santa Cruz, CA) and Amersham ECL Prime Western Blotting Detection Reagent (GE Healthcare Life Sciences), then exposed to $\mathrm{X}$-ray film. Band densitometry analysis was determined using Image software (NIH). Samples were normalized to GADH levels, and a control sample was resolved on each gel. Additionally, phosphorylation levels were normalized to their corresponding total protein after membranes were stripped, as previously reported [44].

\section{Statistics}

Analyses were performed using SPSS version 21.0 software (SPSS Inc., Chicago, IL). Comparisons between bGH mice and WT controls were analyzed using unpaired $t$ test comparisons. Pearson correlation coefficients were used to determine relationships between proteins. Data are presented as means \pm SEM unless otherwise noted. Statistical significance was defined as $P<0.05$.

\section{Results}

\section{Body weight and gastrocnemius mass}

Total body mass was significantly increased in bGH mice compared to WT controls $(49 \%, P<0.0001$, Table 1$)$. Mice overexpressing $\mathrm{GH}$ had increased soleus muscle mass (44\%, $P<0.0001$, Table 1) and a tendency for increased gastrocnemius muscle mass $(P=0.06$, Table 1$)$ compared to controls; however, the gastrocnemius was lower $(-28 \%$, $P<0.0001$, Table 1) and the soleus did not differ $(P=0.44)$ when expressed relative to total body weight.

\section{Skeletal muscle JAK2-STAT5 pathway}

Tyrosine phosphorylation of STAT5 was increased in the gastrocnemius of bGH mice compared to WT controls only when expressed relative to total protein $(96 \%$, $P<0.05$, Fig. 1c). JAK2 phosphorylation relative to total JAK2 protein in the gastrocnemius did not differ between mice overexpressing $\mathrm{GH}$ and controls $(P=0.12$, Fig. 1f). Total STAT5 and JAK2 protein were significantly lower in the gastrocnemius of bGH mice $(-38 \%$, Fig. $1 \mathrm{~b}$ and $-40 \%$, Fig. 1e, respectively, $P<0.05)$. Due to limited soleus tissue, JAK2 and STAT5 analyses were only completed in a subset of WT $(n=5)$ and bGH $(n=4)$ mice; however, similar trends were observed in the soleus as in the gastrocnemius.

\section{Skeletal muscle Akt/mTOR pathway}

Skeletal muscle Akt1 phosphorylation on site Ser473 was $72 \%$ higher in the gastrocnemius of bGH compared to WT mice $(P<0.05$, Fig. 2a). Similarly, the soleus of bGH mice had increased phosphorylation levels of Akt1 Ser473 (86\%, $P<0.005$, Fig. $2 b)$ compared to controls. The gastrocnemius of bGH had decreased Akt2 phosphorylation on site Ser474 compared to WT mice (-37\%, $P<0.05$, Fig. 2c), whereas no significant differences in Akt2 serine phosphorylation were detected between the two groups of mice in the soleus (Fig. 2d). Total Akt1 was 76 and $179 \%$ higher in the gastrocnemius $(P<0.05$, Fig. $2 \mathrm{a})$ and soleus $(P<0.0005$, Fig. $2 \mathrm{~b})$, respectively, of the bGH mice compared to WT controls. Total Akt2 was $50 \%$ lower $(P<0.005$, Fig. 2 c) in the gastrocnemius of bGH mice compared to their WT

Table 1 Mass of whole body, gastrocnemius, and soleus in bGH and WT mice

\begin{tabular}{lll}
\hline & WT mice & bGH mice \\
\hline Whole body mass (g) & $30.44 \pm 1.78$ & $45.22 \pm 2.91 *$ \\
Gastrocnemius mass (g) & $0.310 \pm 0.019$ & $0.332 \pm 0.027+$ \\
Gastrocnemius/body mass (g) & $0.0102 \pm 0.0007$ & $0.0073 \pm 0.0004$ * \\
Soleus mass (g) & $0.017 \pm 0.002$ & $0.024 \pm 0.003 *$ \\
Soleus/body mass (g) & $0.0006 \pm 0.00006$ & $0.0005 \pm 0.00004$ \\
\hline
\end{tabular}

Mass of both gastrocnemius and soleus. Data are presented mean \pm SD WT wild type control mice $(n=9)$, bGH bovine growth hormone mice $(n=9)$ ${ }^{*} P<0.0001$ vs. WT mice, $+P=0.06$ vs. WT mice 

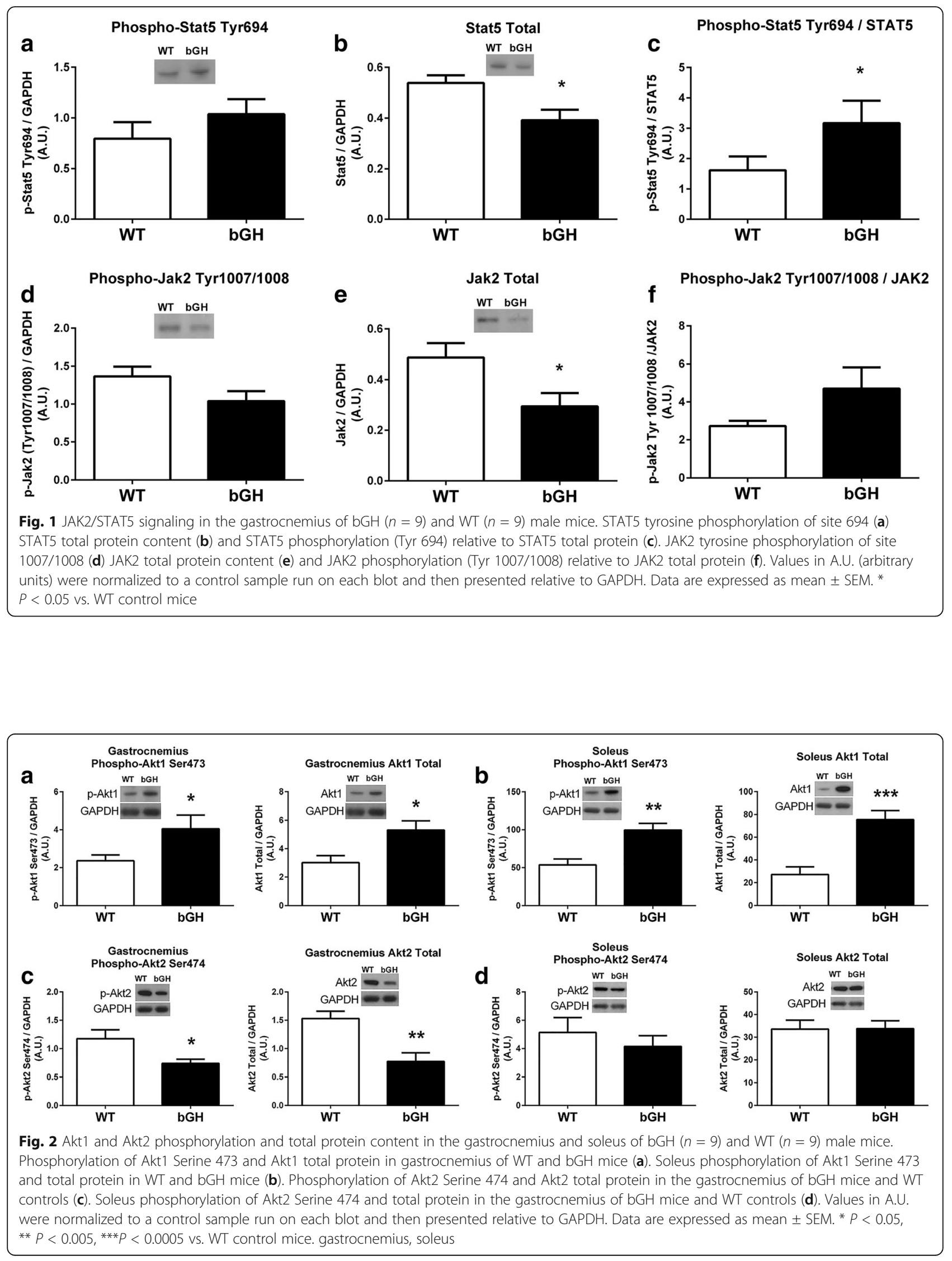
counterparts, whereas Akt2 protein content did not differ in the soleus (Fig. 2d). When phosphorylation was normalized to the corresponding Akt isoform, no differences existed between the two groups of mice, with the exception of the soleus of WT mice that had an increase in serine 473 phosphorylation on Akt1 relative to total protein $(44 \%, P<0.05)$.

mTOR protein was significantly depressed in the gastrocnemius of bGH mice compared to WT controls $(-85 \%, P<0.01$, Fig. 3a) with no statistical differences noted in the phosphorylation of mTOR in the gastrocnemius $(P=0.13$, Fig. $3 \mathrm{a})$ or soleus $(P=0.45$, Fig. $3 \mathrm{~b})$. Phosphorylation of 4EBP1 and p70 kinase were significantly increased in the gastrocnemius (92 and $55 \%$, respectively, $P<0.001$, Fig. $3 \mathrm{c}$, e) and soleus (37\%, $P<0.01$ and $34 \%, P<0.05$, respectively, Fig. 3d, f) of bGH mice, with no differences in total protein (Fig. 3c-f). GSK3 $\beta$ and FOXO1 phosphorylation, as well as, total protein did not differ between bGH and WT mice (not shown). When phosphorylated proteins were normalized to respective total protein, only p70 S6 kinase phosphorylation levels in the gastrocnemius were significantly elevated in the bGH mice compared to WT controls (78\%, $P<0.005$, not shown).
Skeletal muscle MAPK pathway

Phosphorylation of p42 and p44 were increased in the gastrocnemius of bGH mice compared to WT littermates $(124 \%, P<0.01$, Fig. $4 \mathrm{a}$ and $111 \%, P<0.05$, Fig. $4 \mathrm{c}$, respectively). Gastrocnemius phosphorylation of $\mathrm{p} 38$ was increased $57 \%(P<0.005$, Fig. $4 \mathrm{e})$ in the bGH mice compared to controls. Phosphorylation of JNK2 was increased in the bGH mice $142 \%(P<0.0005$, Fig. $4 \mathrm{~g})$ and $75 \%(P<0.05$, Fig. $4 \mathrm{~h})$ in the gastrocnemius and soleus, respectively. Total p42 and p38 were increased in the gastrocnemius (102\%, $P<0.005$, Fig. $4 \mathrm{a}$, and $31 \%$, $P<0.05$, Fig. 4e, respectively) of bGH mice, whereas total JNK2 was decreased $-23 \%$ in the gastrocnemius $(P<0.005$, Fig. $4 \mathrm{~g})$ and $-54 \%$ in the soleus $(P<0.01$, Fig. 4h) of bGH mice compared to control mice. When phosphorylated proteins were normalized to respective total protein, only JNK2 phosphorylation was significantly increased in the gastrocnemius $(220 \%, P<0.0001$, not shown) and soleus (510\%, $P<0.05$, not shown) (blots, Fig. 5).

\section{Skeletal muscle MuRF1 protein}

MuRF1 protein content was elevated in the gastrocnemius $(30 \%, P<0.05$, Fig. $6 a)$, but not the soleus

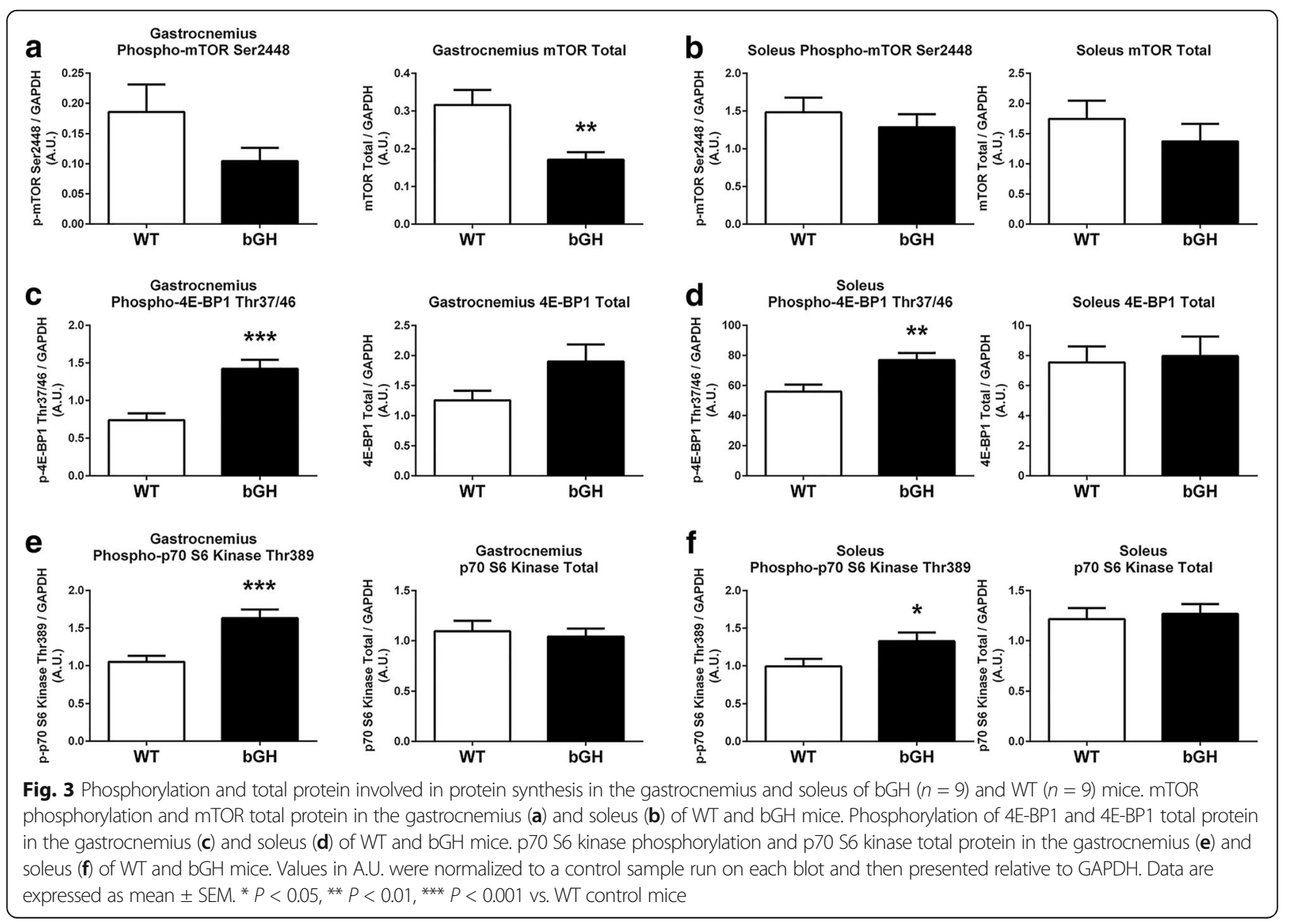



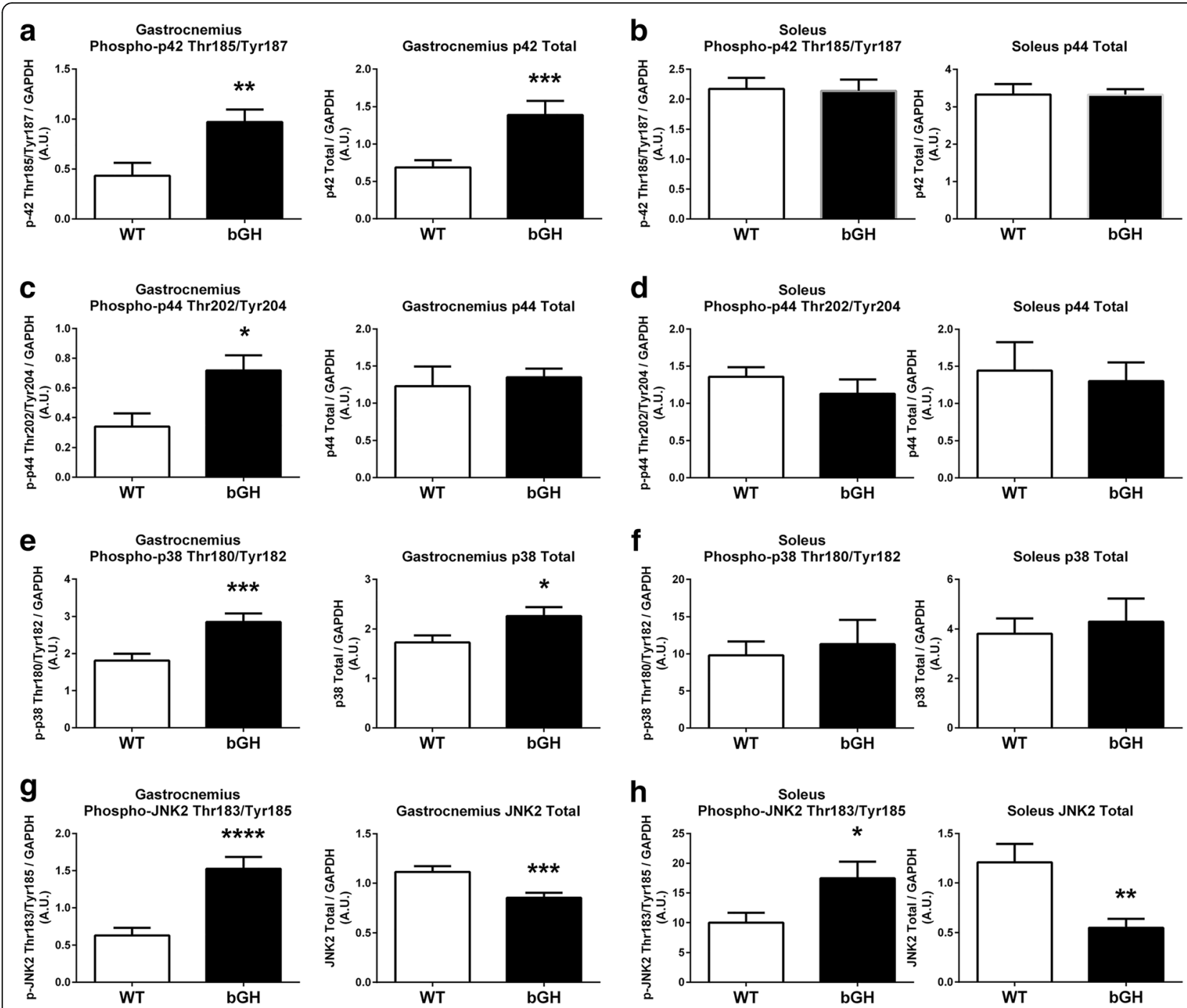

Fig. 4 MAPK phosphorylation and protein content in gastrocnemius and soleus of bGH and WT mice. Phosphorylation of p42 and total p42 in the gastrocnemius (a) and the soleus (b) of WT and bGH mice. p44 phosphorylation and p44 total protein in the gastrocnemius (c) and soleus (d) of WT and bGH mice. Phosphorylation of p38 and total p38 in the gastrocnemius (e) and the soleus (f) of WT and bGH mice JNK2 phosphorylation and JNK2 total protein in the gastrocnemius $(\mathbf{g})$ and the soleus (h) of WT and bGH mice. Values in A.U. were normalized to a control sample run on each blot and then presented relative to GAPDH. Data are expressed as mean \pm SEM. ${ }^{*} P<0.05$, ${ }^{* *} P<0.01$, ${ }^{* * *} P<0.005$, ***P $<0.0005$ vs WT control mice. bGH $(n=9)$ and WT $(n=9)$ for each protein with the exception of (c) gastrocnemius p44 phosphorylation and p44 total protein ( $n=7$ in each group)

$(P=0.94)$, of bGH mice compared to their WT counterparts. Gastrocnemius MuRF1 was not significantly associated with gastrocnemius mass relative to body weight $(r=-0.43, P=0.08)$.

\section{Skeletal muscle myostatin and Smad2/3 pathway}

The gastrocnemius and soleus of bGH mice had higher levels of mature myostatin $(138 \%, P<0.0005$, Fig. 7 a and $128 \%, P<0.05$, Fig. $7 \mathrm{~b}$, respectively), precursor myostatin (66\%, $P<0.0005$, Fig. 7 a and $73 \%, P<0.05$, Fig. $7 \mathrm{~b}$, respectively), and the myostatin receptor, activin receptor type IIB (AcvR2B) $(152 \%, P<0.0005$, Fig. $7 \mathrm{e}$ and $82 \%, P<0.01$, Fig. 7f) compared to WT mice. Phosphorylation of STAT5 was significantly associated with precursor myostatin $(r=0.69, P<0.005$, Fig. $7 \mathrm{~g})$ in the gastrocnemius of the whole group. Gastrocnemius premature myostatin $(r=-0.70, P<0.005$, Fig. 7h) and mature myostatin $(r=-0.69, P<0.005$, not shown $)$ were negatively associated with the gastrocnemius mass relative to body weight. Phosphorylation of mothers against decapentaplegic homolog (Smad2) on serine site $465 / 467$ was increased in the gastrocnemius $(59 \%$, $P<0.0005)$ and the soleus $(43 \%, P<0.05)$ of the bGH compared to WT mice. The gastrocnemius and soleus of 


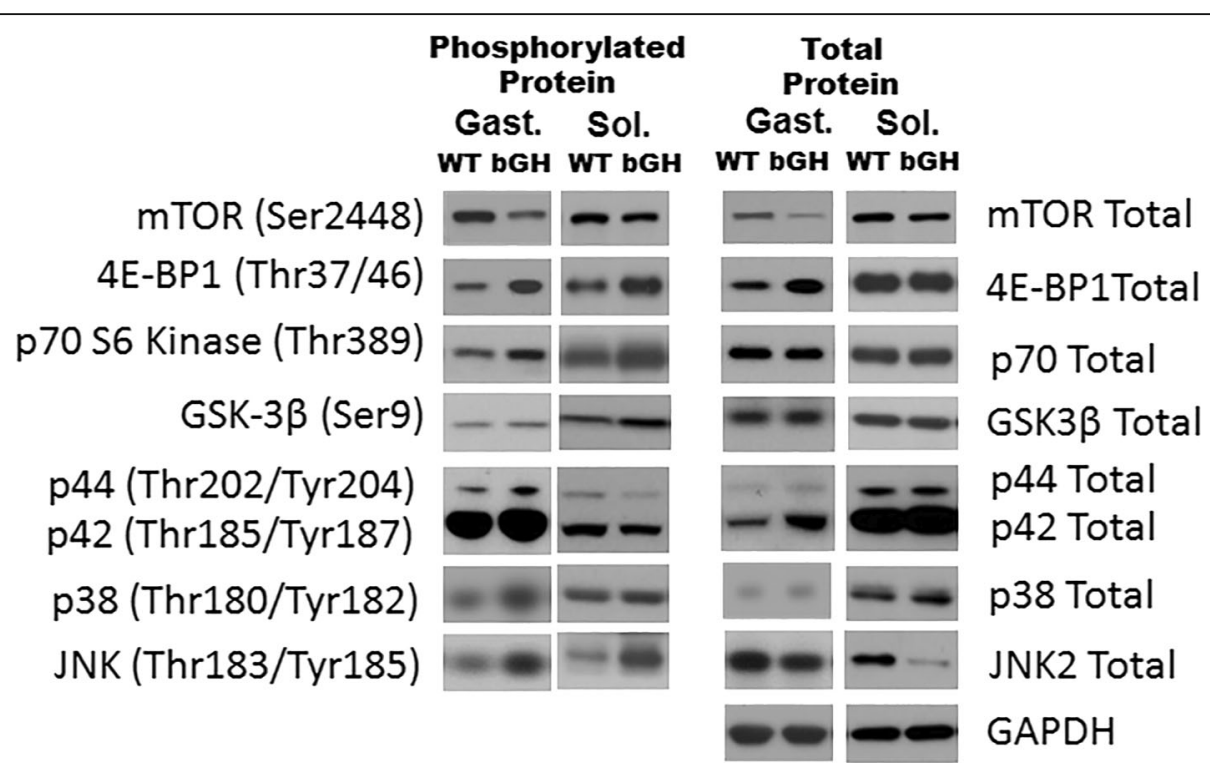

Fig. 5 Representative blots for the mTOR (Fig. 3) and the MAPK pathway (Fig. 4) in the gastrocnemius and soleus of WT and bGH mice. Gast gastrocnemius, Sol soleus

bGH mice had a 400\% ( $P<0.005$, Fig. 6e $)$ and $82 \%$ $(P<0.01)$ increase in phosphorylation levels of Smad2 in the linker region (serine sites 245/250/255) compared to their WT controls. Phosphorylation of Smad3 on serine site 423/425 in the gastrocnemius and soleus did not differ between the two groups of mice. In the whole group, mature myostatin was positively associated with phosphorylation on the Smad2 serine site 423/425 in the soleus ( $r=0.47, P<0.05$, not shown) and the gastrocnemius ( $r=0.33, P<0.05$, not shown), but not on Smad3 serine site $423 / 425(P>0.22)$ or the Smad2 linker region $(P>0.30)$. There were no differences in Smad2 or Smad3 (blots, Fig. 7i) total protein between bGH and WT mice.
Myosin heavy chain (MHC) I and Ilb

MHC I was increased $112 \%$ in the gastrocnemius $(P<0.0001$, Fig. $8 \mathrm{a})$ and $163 \%$ in the soleus $(P<0.01$, $n=4 \mathrm{WT}$ and $n=5 \mathrm{bGH}$, Fig. $8 \mathrm{~b})$ of bGH mice compared to the WT mice. Gastrocnemius MHC IIb did not differ between the two groups of mice ( $P=0.20$, Fig. $8 \mathrm{c})$. MHC IIb was undetectable in the soleus muscle of both the bGH and WT mice.

Insulin signaling intermediates

Gastrocnemius and soleus insulin receptor beta levels were significantly reduced in bGH mice compared to WT controls $(-47 \%, P<0.0001$ and $-41 \% P<0.05$, respectively, Table 2). Phosphorylation on insulin receptor
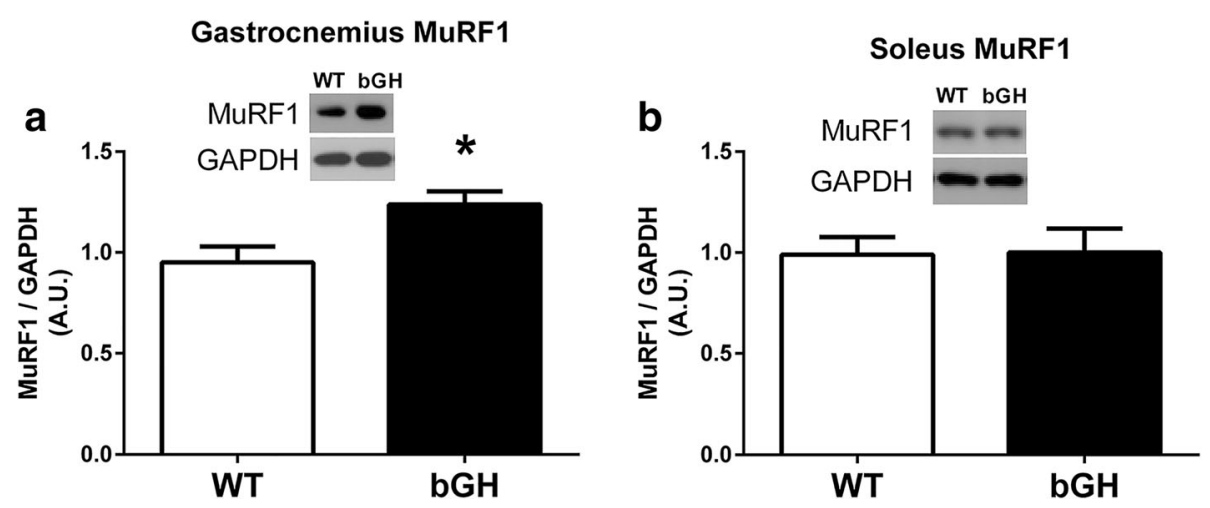

Fig. 6 Skeletal muscle MuRF1 protein expression in bGH $(n=9)$ and WT $(n=9)$ mice. Gastrocnemius (a) and soleus (b) MuRF1 protein expression in bGH and WT mice. Values in A.U. were normalized to a control sample run on each blot and then presented relative to GAPDH. Data are expressed as mean \pm SEM. ${ }^{*} P<0.05$ vs WT control mice 

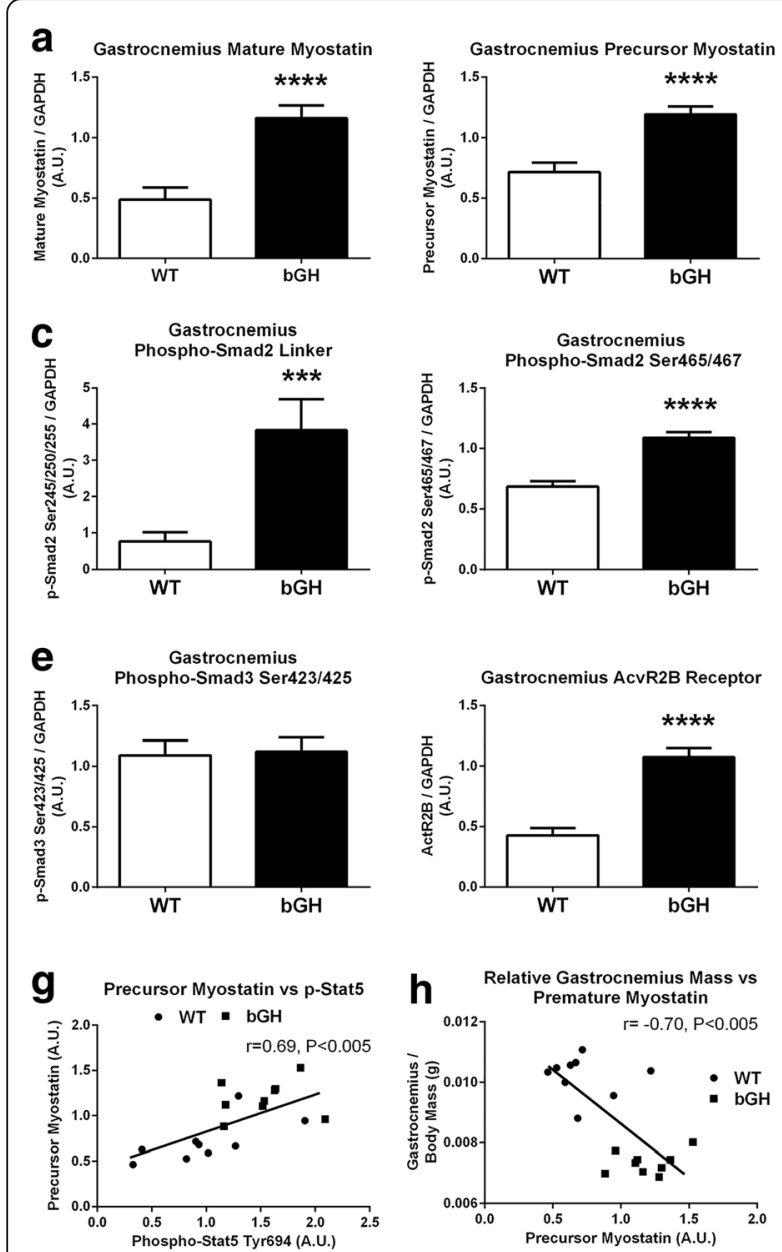
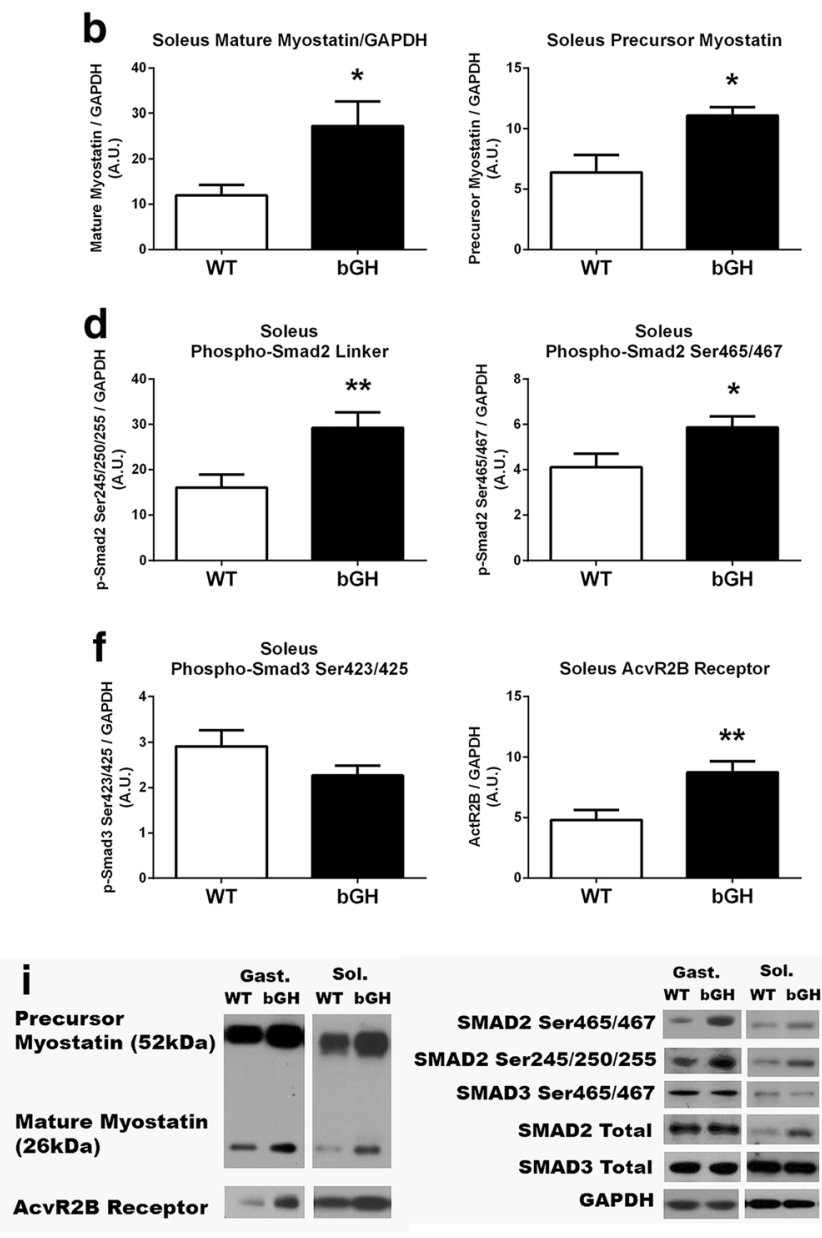

Fig. 7 Myostatin signaling in the gastrocnemius and soleus of bGH $(n=9)$ and WT $(n=9)$ mice. Mature and precursor myostatin protein content in the gastrocnemius (a) and soleus (b) of WT and bGH mice. Phosphorylation of Smad2 (Ser245/250/255) and (Ser465/467) in the gastrocnemius (c) and soleus (d) of WT and bGH mice. Phosphorylation of Smad3 (Ser 423/425) and AcvR2B total protein in the gastrocnemius (e) and soleus (f) of WT and bGH mice. Relationship between Precursor Myostatin and STAT5 phosphorylation in gastrocnemius of bGH and WT skeletal muscle (g). Relationship between relative gastrocnemius mass and precursor myostatin in the gastrocnemius of bGH and WT skeletal muscle (h).

Representative blots in the gastrocnemius and soleus of WT and bGH mice (i). Values in A.U. were normalized to a control sample run on each blot and then presented relative to GAPDH. Data are expressed as mean \pm SEM. ${ }^{*} P<0.05,{ }^{* *} P<0.01,{ }^{* * *} P<0.005{ }^{* * * *} P<0.0005$ vs. WT control mice. Gast, gastrocnemius; Sol, soleus

substrate 1 (IRS1) serine site 307 was significantly increased in the gastrocnemius $(44 \%, P<0.05$, Table 2$)$, but not soleus $(P=0.10)$ of bGH mice. There was a trend for IRS1 total protein to be increased in the gastrocnemius of bGH compared to controls $(62 \%$, $P=0.06$, Fig. $7 \mathrm{~b})$, but not the soleus $(P=0.30)$.

Phosphorylation of Akt substrate of $160 \mathrm{kDa}$ (AS160) on serine site 666 was significantly elevated in the gastrocnemius $(72 \%, P<0.05$, Table 2$)$ and phosphorylation of TBC1 domain family member 1 (TBC1D1) on Thr590 was significantly decreased in the soleus $(-31 \%$, $P<0.05$, Table 2) of bGH compared to WT mice. Phosphorylation on AS160 site Ser588 and TBC1D1 site Ser700 did not differ between the two groups of mice. Total AS160 and TBC1D1 were higher in the gastrocnemius of bGH compared to WT mice (48 and $65 \%$, respectively, $P<0.05$, Table 2 ) but did not differ in the soleus. When individual phosphorylation sites were normalized to respective total protein, no differences were detected for AS160 or TBC1D1.

\section{Discussion}

The main finding in the current study was that chronic elevations in the GH/IGF axis regulate critical signaling pathways involved in both skeletal muscle protein synthesis and atrophy. Transgenic bGH mice have elevations in Akt1 expression and increased phosphorylation of downstream targets responsible for muscle hypertrophy. However, these mice also show increased intramuscular signaling typically associated 

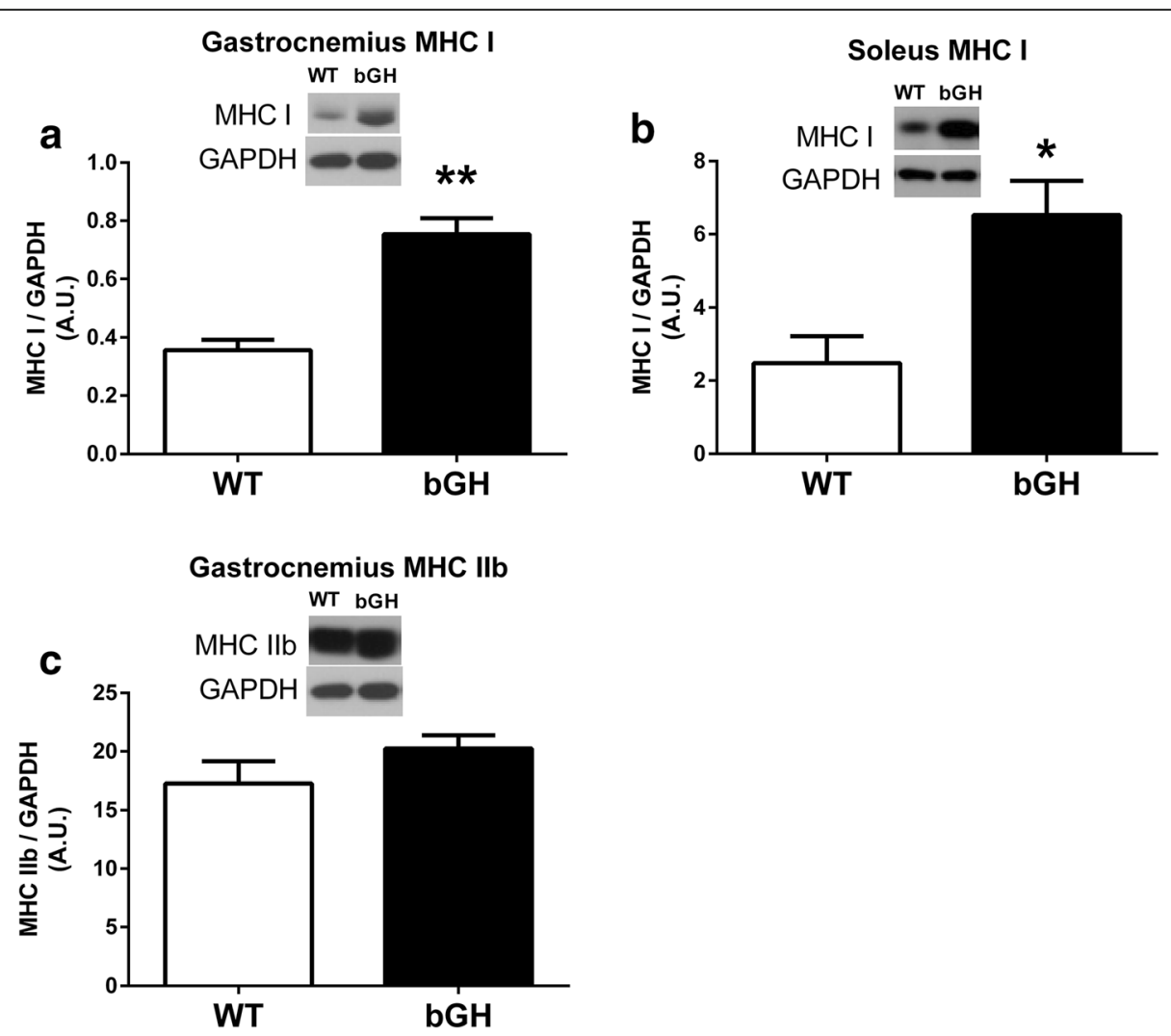

Fig. 8 Skeletal muscle MHC in WT $(n=9)$ and bGH $(n=9)$ mice. Gastrocnemius (a) and soleus (b) MHC I protein expression in WT and bGH mice. Gastrocnemius (c) MHC Ilb in WT and bGH mice. Values in A.U. were normalized to a control sample run on each blot and then presented relative to GAPDH. Data are expressed as mean \pm SEM. ${ }^{*} P<0.05$, ${ }^{* *} P<0.0001$ vs. WT control mice. Gast gastrocnemius, Sol soleus

with skeletal muscle atrophy. We provide novel evidence that MuRF1 is upregulated in a muscle groupdependent manner in bGH mice. We also demonstrate for the first time that myostatin, its receptor (AcvR2B), and part of its canonical pathway (Smad2) are upregulated in the skeletal muscle of mice overexpressing GH. Taken together, our findings suggest that in environments of chronic $\mathrm{GH}$ and/or IGF-1 excess, MuRF1 and myostatin may act to inhibit excess muscle growth, especially in skeletal muscle containing a high proportion of fast twitch fibers.

To our knowledge, this is the first study to provide evidence that $\mathrm{GH}$ regulates Akt in an isoform dependent manner (Fig. 2). One of the primary mechanisms by which GH/IGF stimulates muscle growth is through the IRS/Akt1/mTOR pathway; therefore, it was not

Table 2 Insulin signaling intermediates

\begin{tabular}{|c|c|c|c|c|}
\hline & \multicolumn{2}{|l|}{ Gastrocnemius } & \multicolumn{2}{|l|}{ Soleus } \\
\hline & WT mice $(n=9)$ & bGH mice $(n=9)$ & WT mice $(n=9)$ & bGH mice $(n=9)$ \\
\hline Insulin receptor $\beta(A U)$ & $1.50 \pm 0.01$ & $0.80 \pm 0.05^{* * *}$ & $2.08 \pm 0.24$ & $1.23 \pm 0.18 *$ \\
\hline p-IRS-1Ser307 (AU) & $0.76 \pm 0.07$ & $1.09 \pm 0.14 *$ & $0.84 \pm 0.23$ & $1.46 \pm 0.25$ \\
\hline IRS1 total (AU) & $1.59 \pm 0.21$ & $2.57 \pm 0.44$ & $1.57 \pm 0.33$ & $1.10 \pm 0.31$ \\
\hline p-AS160 16 er588 (AU) & $0.40 \pm 0.03$ & $0.49 \pm 0.05$ & $1.67 \pm 0.40$ & $1.85 \pm 0.29$ \\
\hline p-AS160 ${ }^{\operatorname{Ser} 666}(A U)$ & $1.08 \pm 0.10$ & $1.89 \pm 0.16^{* *}$ & $1.76 \pm 0.31$ & $2.11 \pm 0.34$ \\
\hline 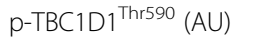 & $0.23 \pm 0.05$ & $0.29 \pm 0.04$ & $1.71 \pm 0.19$ & $1.18 \pm 0.16 *$ \\
\hline p-TBC1D1 ${ }^{\operatorname{Ser} 700}(\mathrm{AU})$ & $0.28 \pm 0.04$ & $0.42 \pm 0.08$ & $1.12 \pm 0.19$ & $0.81 \pm 0.22$ \\
\hline AS160 (AU) & $0.50 \pm 0.04$ & $0.74 \pm 0.08 *$ & $1.63 \pm 0.20$ & $1.52 \pm 0.25$ \\
\hline TBC1D1 (AU) & $0.25 \pm 0.03$ & $0.42 \pm 0.06 *$ & $1.47 \pm 0.18$ & $1.06 \pm 0.18$ \\
\hline
\end{tabular}

Data are expressed as mean \pm SEM

${ }^{*} P<0.05$ vs. WT mice; ${ }^{* *} P<0.001$ vs. WT mice; ${ }^{* *} P<0.0001$ vs. WT mice 
surprising that total Akt1 was upregulated in both the gastrocnemius and soleus of bGH mice (Fig. 2a, b). The current study also provides novel evidence that protein synthesis pathways downstream of Akt1, including the $4 \mathrm{E}-\mathrm{BP} 1$ and p70 kinase pathways are increased in the skeletal muscle of bGH mice (Fig. 3c-f). Protein synthesis involves a complex series of events starting with the translation initiation step and the assembly of the eIF4G-eIF4E complex [46]. In the unphosphorylated form, 4E-BP1 binds to the eukaryotic translation initiation factor 4E (eIF4E) protein, inhibiting it from binding to the extracellular signal-regulated kinase (eIF4G) subunit and consequently repressing translation initiation. Hyperphosphorylation of 4E-BP1, similar to that observed in bGH mice (Fig. 3c), allows 4E-BP1 to dissociate from eIF4E, increasing the availability of eIF4E to bind to eIF4G and increasing protein translation. Mice overexpressing GH also demonstrated increased phosphorylation of the p70 S6 kinase (Fig. 3e-f), a protein critical for the activation of downstream targets responsible for the translation of elongation factors and cell growth [47]. While these results clearly provide evidence that aspects of the Akt1 signaling pathway are upregulated in the skeletal muscle of bGH mice, we also provide novel findings demonstrating that portions of this pathway are unaffected (i.e., GSK3 $\beta$ and FOXO1) or even negatively affected, as is the case for the gastrocnemius (i.e., Akt2 and mTOR, Figs. 2c and 3a), which would contradict previous observations in the liver of bGH mice [48-50]. Taken together, our data indicates that portions of the Akt1 pathway, especially in the gastrocnemius, become less sensitive to chronic elevations in GH/IGF compared to other organs, including the liver [39, 48, 49], and could contribute to the inhibition of excess skeletal muscle growth.

Despite not measuring protein synthesis rates in the present study, lean body mass of bGH mice has been reported to plateau by 4 months of age [39]. Of particular interest, we observed a dramatic decrease in the gastrocnemius mass, after normalizing it to total body mass in bGH mice compared to controls (Table 1). This attenuation of muscle growth occurs in spite of plasma $\mathrm{GH}$ and IGF-1 concentrations being elevated approximately 400 and $80 \%$, respectively, over controls [51]. In an attempt to examine if chronic elevations of GH/IGF-1 affect signaling pathways responsible for inhibiting muscle growth, we measured MuRF1, as well as, myostatin and its canonical signaling pathway. Myostatin was elevated in both the soleus and gastrocnemius of bGH mice (Fig. 7a-b), whereas MuRF1 increased only in the latter (Fig. 6). Similar muscle specific increases in MuRF1 have been observed in other models of atrophy [52]. Given the dramatic decline in gastrocnemius muscle mass relative to the total body mass in bGH mice, the muscle-specific upregulation of MuRF1 could contribute to the inhibition of growth in this muscle. To our knowledge, this is the first study to report an increase in MuRF1 expression in a model of chronic GH excess. It remains unclear if the gastrocnemius specific upregulation of MuRF1 is a direct or indirect consequence of excess GH. Despite not observing differences in FOXO1, a known regulator of MuRF1, a number of other stimuli including inflammation and TNF-alpha have been reported to increase this protein [52] and could have played a role. Phosphorylation of skeletal muscle JNK, a pathway typically activated by inflammatory cytokines, was dramatically increased in bGH mice (Fig. 4g), and others have reported elevated TNF-alpha levels in mice overexpressing GH [53], which could have played a role in regulating MuRF1 expression.

In contrast to our findings with MuRF1, myostatin was elevated in both the gastrocnemius and soleus muscle of bGH mice. Myostatin is originally synthesized in skeletal muscle in its precursor form $(52 \mathrm{kDa})$ and then subsequently modified to the mature myostatin form $(26 \mathrm{kDa})$ through a series of proteolysis steps. A novel finding in the current study was that STAT5 phosphorylation levels were associated with myostatin precursor levels (Fig. 7g), lending support to previous conclusions that $\mathrm{GH}$ post-receptor signaling may play a role in regulating myostatin [54]. Myostatin inhibits skeletal muscle growth by binding to the myostatin receptor (AcvR2B), leading to phosphorylation of Smad2 and Smad3, which then form a heterodimer with Smad4 to translocate to the nucleus to regulate gene transcription. To our knowledge, this is the first study to demonstrate that the myostatin receptor along with Smad2 phosphorylation (Fig. 7c-d) are elevated in a model of $\mathrm{GH}$ excess. A somewhat unexpected finding was that Smad3 phosphorylation did not differ between the two groups of mice (Fig. 7e-f). While the regulation and function of Smad2 and Smad3 have primarily been considered analogous, the current study, along with others [55-57], suggests these two proteins may be regulated differently and have independent physiological roles under certain environmental conditions. IGF-1induced Akt stimulation has recently been shown to inhibit Smad3 phosphorylation in skeletal muscle cells (myoblasts) [58] and has been reported to selectively inhibit Smad3 phosphorylation with no effect on Smad2 phosphorylation in NRP-152 cells [59]. Therefore, it is conceivable that the chronic elevations of IGF-1 in bGH mice blocked the myostatin-induced Smad3 phosphorylation, without having an effect on SMAD2 phosphorylation.

Given the differing effects of $\mathrm{GH}$ excess on the two muscle groups with respect to relative muscle mass (Table 1), the role of increased myostatin signaling in 
bGH remains unclear. However, given the strong negative association between myostatin levels and relative gastrocnemius muscle mass (Fig. $7 \mathrm{~h}$ ), along with the known preferential action of myostatin on type 2 muscle fibers $[30,60,61]$, it is conceivable that the catabolic actions of myostatin are more prevalent in the gastrocnemius than soleus during excess GH/IGF-1 to protect this muscle against excess muscle growth. Similar findings have been described in cardiac tissue, where myostatin has been reported to act as a chalone during conditions of elevated IGF-1 [33, 34]. Collectively, these findings suggest that chronic elevations in GH/IGF-1 may stimulate increased MuRF1 and myostatin protein expression as a mechanism to counterbalance excess stimulation of protein synthesis in skeletal muscle and may contribute to the decrease in gastrocnemius mass with respect to other muscle and organs in bGH mice.

The downstream pathway involved in insulin-induced glucose uptake (AS160 and TBC1D1) appears to be relatively unaffected in bGH mice, at least in the fasted state (Table 2). This finding was somewhat unexpected given the elevated insulin levels in bGH mice of this age [39] and could suggest inhibitory mechanism(s) located upstream. Consistent with previous findings in skeletal muscle [37] and liver [40], we observed diminished insulin receptor expression in the skeletal muscle of bGH mice compared to their WT counterparts (Table 2). Previous research has shown enhanced phosphorylation of IRS1 at Ser 612 and Ser 636/639 in the heart of bGH mice [62]; however, we believe this is the first study to report increased skeletal muscle phosphorylation of IRS1 on serine site 307 , in a model of GH excess. Based on our findings that the elevated IRS serine phosphorylation occurred only in the gastrocnemius, it is possible this effect is specific to glycolytic muscle. This observation has significant implications since IRS1 serine phosphorylation on site 307 inhibits both insulin and IGF-1 signal transduction and has become synonymous with conditions of insulin/IGF-1 resistance [63-65], muscle atrophy [66], and inflammation [65]. Increased serine phosphorylation of IRS1 could provide a novel mechanism to explain the insulin resistance reported in bGH mice [37, 40, 41] and could play a role in inhibiting excess IGF-1 signaling in the gastrocnemius. Since both insulin and IGF-1 are known to increase serine phosphorylation of IRS1, it is not unrealistic to suggest that the chronic, elevated levels of these hormones in bGH mice stimulates the serine phosphorylation of IRS1 as another means to counter regulate excess IGF1/Akt1 signaling and prevent excess muscle growth.

The MAPK pathway (ERK and p38) is another pathway stimulated by GH and IGF-1, independent of IRS/ Akt, and is critical for the growth and maintenance of skeletal muscle. Of particular interest, the MAPK response to excess $\mathrm{GH} / \mathrm{IGF}-1$ appeared to be muscle group specific, with increased phosphorylation of p42/44 and p38 only occurring in the gastrocnemius of bGH mice. The increased protein content of p42 and p38 likely contributed, at least in part, to the increased phosphorylation levels of the proteins. Research investigating the effects of chronic $\mathrm{GH}$ overexpression on the liver have reported the upregulation of both $\mathrm{p} 42 / \mathrm{p} 44$ protein $[48,67]$ and somewhat surprisingly, decrements in p38 phosphorylation [68]. While the mechanism responsible for these conflicting findings remain unknown, it could be related to the tissue-specific role of this pathway in muscle cell differentiation [19] and transcriptional regulation of muscle-specific genes [69].

It has previously been determined that the gastrocnemius of mice consists of 3\% type I fibers and $55-80 \%$ type IIb fibers, whereas the soleus consists of $30-40 \%$ type I and $~ 3 \%$ type IIb [70, 71] allowing us to examine the effects of chronic GH/IGF-I in separate muscle groups that contain two differing muscle fiber type composition. Our finding that bGH mice had a higher proportion of MHC I protein in both their gastrocnemius (Fig. 8a) and soleus (Fig. 8b) is in line with previous research in bGH mice [42]. The current study did not measure muscle fiber cross-sectional area (CSA), but others have reported that an increase in muscle fiber CSA is primarily in oxidative muscle fibers (type I and IIA), without any significant changes in glycolytic type IIb fibers [42]. GH is known to have metabolic properties promoting lipid oxidation and sparing glucose oxidation [72] which could stimulate the transition of the muscle to a more oxidative fiber type. The cellular mechanism(s) responsible for the preferential switch to more oxidative muscle fibers during $\mathrm{GH}$ excess remains unclear; however, a unique finding in the current study was the upregulation of myostatin in muscle demonstrating an increase in MHC I. In addition to the well-documented regulation of muscle mass, myostatin also plays an important role in determining skeletal muscle fiber composition [30]. Animal models deficient in myostatin have increased muscle mass, with a specific increase in fast glycolytic muscle [30, 60, 61]. Therefore, in addition to the potential role in inhibiting excess muscle growth, the increased myostatin levels could have contributed, at least in part, to the increase in MHC I in both the soleus and gastrocnemius of bGH mice.

\section{Conclusions}

The current study demonstrates for the first time the upregulation of a number of cellular mechanisms involved in both skeletal muscle hypertrophy and atrophy under conditions of excess GH/IGF-1. This study also highlights the muscle specific increases in MuRF1 
and IRS1 serine phosphorylation that parallel the more dramatic inhibition of muscle growth in the gastrocnemius compared to the soleus of bGH mice. We also provide insight into the elevation of myostatin and MHC I in bGH mice, regardless of muscle type. Taken together, the current study provides critical insight into the signaling pathways involved in regulating skeletal muscle mass under conditions of excess GH/IGF and highlights the importance of fiber type specific studies when investigating the effects of $\mathrm{GH}$ on skeletal muscle signaling and muscle growth.

\begin{abstract}
Abbreviations
4E-BP1: 4E-binding protein 1; A.U.: Arbitrary unit; AcvR2B: Activin receptor type-2B; AIDS: Acquired immune deficiency syndrome; Akt: Protein kinase b; AS160: Akt substrate of $160 \mathrm{kDa}$; bGH: Bovine growth hormone; $\mathrm{CO}_{2}$ : Carbon dioxide; COPD: Chronic obstructive pulmonary disease; elF4E: Eukaryotic translation initiation factor 4E; elF4G: Eukaryotic translation initiation factor 4G; ERK: Extracellular signal-regulated kinase; FOX: Forkhead box; GAPDH: Glyceraldehyde 3-phosphate dehydrogenase; Gast: Gastrocnemius; GH: Growth hormone; GSK3: Glycogen synthase kinase; IGF: Insulin-like growth factor; IRS1: Insulin receptor substrate 1; JAK2: Janus kinase 2; JNK: cJun N-terminal kinase; MAPK: Mitogen-activated protein kinase; MHC: Myosin heavy chain; mTOR: Mechanistic target of rapamycin; MuRF1: Muscle RING finger 1; NT: Non-transgenic; p70 S6 Kinase (Thr389): Ribosomal protein S6 kinase; PCR: Polymerase chain reaction; SDS-PAGE: Sodium dodecyl sulfate polyacrylamide gel electrophoresis; SEM: Standard error of mean; Ser: Serine; SMAD: Mothers against decapentaplegic homolog; Sol: Soleus; Stat: Signal transducer and activator of transcription; TBC1D1: TBC1 domain family member 1 ; TGF- $\beta$ : Transforming growth factor- $\beta$; Thr: Threonine; Tyr: Tyrosine; WT: Wild type
\end{abstract}

\section{Acknowledgements}

Not applicable

\section{Competing interests}

The authors declare that they have no competing interests.

\section{Funding}

This work was supported by grants from the National Institutes of Health (DK102115) and Diabetes Action to L.A.C. J.J.K. is supported, in part, by the State of Ohio's Eminent Scholar Program that includes a grant from Milton and Lawrence Goll.

\section{Availability of data and materials}

The datasets used and/or analyzed during the current study are available from the corresponding author on reasonable request.

\section{Authors' contributions}

LAC wrote the manuscript and helped in the experimental design, Western blot analysis, and statistical analysis. AS and GS performed the Western blot analysis. EOL helped in the experimental design, data collection, and editing of the manuscript. JJK helped in experimental design and editing of the manuscript. All authors read and approved the final manuscript.

\section{Ethics approval}

All procedures performed with the mice were approved by the Institutional Animal Care and Use Committee at Ohio University and are in accordance with all standards set forth by federal, state, and local authorities.

\section{Consent for publication}

Not applicable.

\section{Publisher's Note}

Springer Nature remains neutral with regard to jurisdictional claims in published maps and institutional affiliations.

\section{Author details}

'Department of Biomedical Sciences, Ohio University, 228 Irvine Hall, Athens, Ohio 45701, USA. ${ }^{2}$ Ohio Musculoskeletal and Neurological Institute, Ohio University, Athens, Ohio 45701, USA. ${ }^{3}$ Diabetes Institute, Ohio University, Athens, Ohio 45701, USA. ${ }^{4}$ Department of Biological Sciences, Ohio University, Athens, Ohio 45701, USA. ${ }^{5}$ Edison Biotechnology Institute, Ohio University, Athens, OH 45701, USA.

Received: 20 February 2017 Accepted: 14 August 2017

Published online: 04 September 2017

\section{References}

1. Trombetti A, Reid KF, Hars M, Herrmann FR, Pasha E, Phillips EM, Fielding RA. Age-associated declines in muscle mass, strength, power, and physical performance: impact on fear of falling and quality of life. Osteoporos Int. 2016;27:463-71.

2. Doherty TJ. Invited review: aging and sarcopenia. J Appl Physiol (1985). 2003;95:1717-27.

3. Martin L, Birdsell L, Macdonald N, Reiman T, Clandinin MT, McCargar L, Murphy R, Ghosh S, Sawyer MB, Baracos VE. Cancer cachexia in the age of obesity: skeletal muscle depletion is a powerful prognostic factor, independent of body mass index. J Clin Oncol. 2013;31:1539-47.

4. Schols AM, Soeters PB, Dingemans AM, Mostert R, Frantzen PJ, Wouters EF Prevalence and characteristics of nutritional depletion in patients with stable COPD eligible for pulmonary rehabilitation. Am Rev Respir Dis. 1993:147:1151-6.

5. Engelen MP, Schols AM, Does JD, Wouters EF. Skeletal muscle weakness is associated with wasting of extremity fat-free mass but not with airflow obstruction in patients with chronic obstructive pulmonary disease. Am J Clin Nutr. 2000;71:733-8.

6. Elkin SL, Williams L, Moore M, Hodson ME, Rutherford OM. Relationship of skeletal muscle mass, muscle strength and bone mineral density in adults with cystic fibrosis. Clin Sci (Lond). 2000;99:309-14.

7. Isaksson OG, Jansson JO, Gause IA. Growth hormone stimulates longitudinal bone growth directly. Science. 1982;216:1237-9.

8. Moller N, Jorgensen JO. Effects of growth hormone on glucose, lipid, and protein metabolism in human subjects. Endocr Rev. 2009;30:152-77.

9. Green H, Morikawa M, Nixon T. A dual effector theory of growth-hormone action. Differentiation. 1985;29:195-8.

10. Fryburg DA, Barrett EJ. Growth hormone acutely stimulates skeletal muscle but not whole-body protein synthesis in humans. Metabolism. 1993:42:1223-7.

11. Fryburg DA, Gelfand RA, Barrett EJ. Growth hormone acutely stimulates forearm muscle protein synthesis in normal humans. Am J Phys. 1991; 260:E499-504.

12. Jorgensen JO, Jessen N, Pedersen SB, Vestergaard E, Gormsen L, Lund SA, Billestrup N. GH receptor signaling in skeletal muscle and adipose tissue in human subjects following exposure to an intravenous GH bolus. Am J Physiol Endocrinol Metab. 2006;291:E899-905.

13. Silva CM, Kloth MT, Whatmore AJ, Freeth JS, Anderson N, Laughlin KK, Huynh T, Woodall AJ, Clayton PE. GH and epidermal growth factor signaling in normal and Laron syndrome fibroblasts. Endocrinology. 2002;143:2610-7.

14. Costoya JA, Finidori J, Moutoussamy S, Searis R, Devesa J, Arce VM. Activation of growth hormone receptor delivers an antiapoptotic signal: evidence for a role of Akt in this pathway. Endocrinology. 1999;140:5937-43.

15. Thirone AC, Carvalho CR, Saad MJ. Growth hormone stimulates the tyrosine kinase activity of JAK2 and induces tyrosine phosphorylation of insulin receptor substrates and Shc in rat tissues. Endocrinology. 1999;140:55-62.

16. Hayashi AA, Proud CG. The rapid activation of protein synthesis by growth hormone requires signaling through mTOR. Am J Physiol Endocrinol Metab. 2007:292:E1647-55.

17. Vanderkuur JA, Butch ER, Waters SB, Pessin JE, Guan KL, Carter-Su C. Signaling molecules involved in coupling growth hormone receptor to mitogen-activated protein kinase activation. Endocrinology. 1997;138:4301-7.

18. Coolican SA, Samuel DS, Ewton DZ, McWade FJ, Florini JR. The mitogenic and myogenic actions of insulin-like growth factors utilize distinct signaling pathways. J Biol Chem. 1997;272:6653-62.

19. Lovett FA, Cosgrove RA, Gonzalez I, Pell JM. Essential role for p38alpha MAPK but not p38gamma MAPK in Igf2 expression and myoblast differentiation. Endocrinology. 2010;151:4368-80. 
20. Li J, Johnson SE. ERK2 is required for efficient terminal differentiation of skeletal myoblasts. Biochem Biophys Res Commun. 2006;345:1425-33.

21. Butterfield GE, Thompson J, Rennie MJ, Marcus R, Hintz RL, Hoffman AR. Effect of rhGH and rhlGF-I treatment on protein utilization in elderly women. Am J Phys. 1997;272:E94-9.

22. Jorgensen JO, Thuesen L, Muller J, Ovesen P, Skakkebaek NE, Christiansen JS. Three years of growth hormone treatment in growth hormone-deficient adults: near normalization of body composition and physical performance. Eur J Endocrinol. 1994;130:224-8.

23. Lange $\mathrm{KH}$, Andersen JL, Beyer $\mathrm{N}$, Isaksson F, Larsson B, Rasmussen $\mathrm{MH}$, Juul $\mathrm{A}$ Bulow J, Kjaer M. GH administration changes myosin heavy chain isoforms in skeletal muscle but does not augment muscle strength or hypertrophy, either alone or combined with resistance exercise training in healthy elderly men. J Clin Endocrinol Metab. 2002;87:513-23.

24. Taaffe $D R$, Jin $I H, V u T H$, Hoffman AR, Marcus R. Lack of effect of recombinant human growth hormone $(\mathrm{GH})$ on muscle morphology and $\mathrm{GH}$-insulin-like growth factor expression in resistance-trained elderly men. J Clin Endocrinol Metab. 1996;81:421-5.

25. Colao A, Ferone D, Marzullo P, Lombardi G. Systemic complications of acromegaly: epidemiology, pathogenesis, and management. Endocr Rev. 2004;25:102-52.

26. Freda PU, Shen W, Reyes-Vidal CM, Geer EB, Arias-Mendoza F, Gallagher D, Heymsfield SB. Skeletal muscle mass in acromegaly assessed by magnetic resonance imaging and dual-photon x-ray absorptiometry. J Clin Endocrinol Metab. 2009;94:2880-6.

27. Mastaglia FL. Pathological changes in skeletal muscle in acromegaly. Acta Neuropathol. 1973;24:273-86.

28. Nagulesparen M, Trickey R, Davies MJ, Jenkins JS. Muscle changes in acromegaly. Br Med J. 1976;2:914-5.

29. Moriscot AS, Baptista IL, Bogomolovas J, Witt C, Hirner S, Granzier H, Labeit S. MuRF1 is a muscle fiber-type II associated factor and together with MuRF2 regulates type-II fiber trophicity and maintenance. J Struct Biol. 2010;170:344-53.

30. Hennebry A, Berry C, Siriett V, O'Callaghan P, Chau L, Watson T, Sharma M, Kambadur R. Myostatin regulates fiber-type composition of skeletal muscle by regulating MEF2 and MyoD gene expression. Am J Physiol Cell Physiol. 2009;296:C525-34.

31. Pickart CM, Eddins MJ. Ubiquitin: structures, functions, mechanisms. Biochim Biophys Acta. 1695;2004:55-72.

32. McPherron AC, Lawler AM, Lee SJ. Regulation of skeletal muscle mass in mice by a new TGF-beta superfamily member. Nature. 1997;387:83-90

33. Shyu KG, Ko WH, Yang WS, Wang BW, Kuan P. Insulin-like growth factor-1 mediates stretch-induced upregulation of myostatin expression in neonatal rat cardiomyocytes. Cardiovasc Res. 2005;68:405-14.

34. Gaussin V, Depre C. Myostatin, the cardiac chalone of insulin-like growth factor-1. Cardiovasc Res. 2005;68:347-9.

35. Bullough WS. Mitotic and functional homeostasis: a speculative review Cancer Res. 1965;25:1683-727.

36. Oldham JM, Osepchook CC, Jeanplong F, Falconer SJ, Matthews KG Conaglen JV, Gerrard DF, Smith HK, Wilkins RJ, Bass JJ, McMahon CD. The decrease in mature myostatin protein in male skeletal muscle is developmentally regulated by growth hormone. J Physiol. 2009;587:669-77.

37. Dominici FP, Cifone D, Bartke A, Turyn D. Alterations in the early steps of the insulin-signaling system in skeletal muscle of GH-transgenic mice. Am J Phys. 1999;277:E447-54.

38. Berryman DE, List EO, Coschigano KT, Behar K, Kim JK, Kopchick JJ. Comparing adiposity profiles in three mouse models with altered $\mathrm{GH}$ signaling. Growth Hormon IGF Res. 2004;14:309-18.

39. Jara A, Benner CM, Sim D, Liu X, List EO, Householder LA, Berryman DE, Kopchick JJ. Elevated systolic blood pressure in male $\mathrm{GH}$ transgenic mice is age dependent. Endocrinology. 2014;155:975-86.

40. Dominici FP, Cifone D, Bartke A, Turyn D. Loss of sensitivity to insulin at early events of the insulin signaling pathway in the liver of growth hormone-transgenic mice. J Endocrinol. 1999;161:383-92.

41. Berryman DE, List EO, Kohn DT, Coschigano KT, Seeley RJ, Kopchick JJ. Effect of growth hormone on susceptibility to diet-induced obesity. Endocrinology. 2006;147:2801-8.

42. Schuenke MD, Kopchick JJ, Hikida RS, Kraemer WJ, Staron RS. Effects of growth hormone overexpression vs. growth hormone receptor gene disruption on mouse hindlimb muscle fiber type composition. Growth Hormon IGF Res. 2008;18:479-86.
43. Wolf E, Wanke R, Schenck E, Hermanns W, Brem G. Effects of growth hormone overproduction on grip strength of transgenic mice. Eur J Endocrinol. 1995;133:735-40.

44. Consitt LA, Saxena G, Saneda A, Houmard JA. Age-related impairments in skeletal muscle PDH phosphorylation and plasma lactate are indicative of metabolic inflexibility and the effects of exercise training. Am J Physiol Endocrinol Metab. 2016;311:E145-56.

45. Consitt LA, Van Meter J, Newton CA, Collier DN, Dar MS, Wojtaszewski JF, Treebak JT, Tanner CJ, Houmard JA. Impairments in site-specific AS160 phosphorylation and effects of exercise training. Diabetes. 2013;62:3437-47.

46. Vary TC, Jefferson LS, Kimball SR. Insulin fails to stimulate muscle protein synthesis in sepsis despite unimpaired signaling to 4E-BP1 and S6K1. Am J Physiol Endocrinol Metab. 2001;281:E1045-53.

47. Dufner A, Thomas G. Ribosomal S6 kinase signaling and the control of translation. Exp Cell Res. 1999:253:100-9.

48. Miquet JG, Gonzalez L, Matos MN, Hansen CE, Louis A, Bartke A, Turyn D, Sotelo Al. Transgenic mice overexpressing GH exhibit hepatic upregulation of $\mathrm{GH}$-signaling mediators involved in cell proliferation. J Endocrinol. 2008;198:317-30.

49. Diaz ME, Gonzalez L, Miquet JG, Martinez CS, Sotelo Al, Bartke A, Turyn D. Growth hormone modulation of EGF-induced PI3K-Akt pathway in mice liver. Cell Signal. 2012;24:514-23.

50. Miquet JG, Freund T, Martinez CS, Gonzalez L, Diaz ME, Micucci GP, Zotta E, Boparai RK, Bartke A, Turyn D, Sotelo Al. Hepatocellular alterations and dysregulation of oncogenic pathways in the liver of transgenic mice overexpressing growth hormone. Cell Cycle. 2013;12:1042-57.

51. Palmer AJ, Chung MY, List EO, Walker J, Okada S, Kopchick JJ, Berryman DE. Age-related changes in body composition of bovine growth hormone transgenic mice. Endocrinology. 2009;150:1353-60.

52. Frost RA, Nystrom GJ, Jefferson LS, Lang CH. Hormone, cytokine, and nutritional regulation of sepsis-induced increases in atrogin-1 and MuRF1 in skeletal muscle. Am J Physiol Endocrinol Metab. 2007;292:E501-12.

53. Wang Z, Masternak MM, Al-Regaiey KA, Bartke A. Adipocytokines and the regulation of lipid metabolism in growth hormone transgenic and calorierestricted mice. Endocrinology. 2007;148:2845-53.

54. Vijayakumar A, Wu Y, Sun H, Li X, Jeddy Z, Liu C, Schwartz GJ, Yakar S, LeRoith D. Targeted loss of GHR signaling in mouse skeletal muscle protects against high-fat diet-induced metabolic deterioration. Diabetes. 2012;61:94-103.

55. Brown KA, Pietenpol JA, Moses HL. A tale of two proteins: differential roles and regulation of Smad2 and Smad3 in TGF-beta signaling. J Cell Biochem. 2007;101:9-33.

56. Piek E, Ju WJ, Heyer J, Escalante-Alcalde D, Stewart CL, Weinstein M, Deng C, Kucherlapati R, Bottinger EP, Roberts AB. Functional characterization of transforming growth factor beta signaling in Smad2- and Smad3-deficient fibroblasts. J Biol Chem. 2001;276:19945-53.

57. Denis JF, Sader F, Gatien S, Villiard E, Philip A, Roy S. Activation of Smad2 but not Smad3 is required to mediate TGF-beta signaling during axolotl limb regeneration. Development. 2016;143:3481-90.

58. Retamales A, Zuloaga R, Valenzuela CA, Gallardo-Escarate C, Molina A, Valdes JA. Insulin-like growth factor-1 suppresses the myostatin signaling pathway during myogenic differentiation. Biochem Biophys Res Commun. 2015;464:596-602.

59. Song K, Cornelius SC, Reiss M, Danielpour D. Insulin-like growth factor-I inhibits transcriptional responses of transforming growth factor-beta by phosphatidylinositol 3-kinase/Akt-dependent suppression of the activation of Smad3 but not Smad2. J Biol Chem. 2003;278:38342-51.

60. Girgenrath S, Song K, Whittemore LA. Loss of myostatin expression alters fiber-type distribution and expression of myosin heavy chain isoforms in slow- and fast-type skeletal muscle. Muscle Nerve. 2005;31:34-40.

61. Stavaux D, Art T, McEntee K, Reznick M, Lekeux P. Muscle fibre type and size, and muscle capillary density in young double-muscled blue Belgian cattle. Zentralbl Veterinarmed A. 1994;41:229-36.

62. Miquet JG, Giani JF, Martinez CS, Munoz MC, Gonzalez L, Sotelo Al, Boparai RK, Masternak MM, Bartke A, Dominici FP, Turyn D. Prolonged exposure to GH impairs insulin signaling in the heart. J Mol Endocrinol. 2011;47:167-77.

63. Lang $\mathrm{CH}$. Elevated plasma free fatty acids decrease basal protein synthesis, but not the anabolic effect of leucine, in skeletal muscle. Am J Physio Endocrinol Metab. 2006;291:E666-74.

64. Yu C, Chen Y, Cline GW, Zhang D, Zong H, Wang Y, Bergeron R, Kim JK, Cushman SW, Cooney GJ, Atcheson B, White MF, Kraegen EW, Shulman Gl. 
Mechanism by which fatty acids inhibit insulin activation of insulin receptor substrate-1 (IRS-1)-associated phosphatidylinositol 3-kinase activity in muscle. J Biol Chem. 2002;277:50230-6.

65. Bandyopadhyay GK, Yu JG, Ofrecio J, Olefsky JM. Increased p85/55/50 expression and decreased phosphotidylinositol 3-kinase activity in insulinresistant human skeletal muscle. Diabetes. 2005;54:2351-9.

66. Hilder TL, Tou JC, Grindeland RE, Wade CE, Graves LM. Phosphorylation of insulin receptor substrate-1 serine 307 correlates with JNK activity in atrophic skeletal muscle. FEBS Lett. 2003;553:63-7.

67. Martinez CS, Piazza VG, Gonzalez L, Fang Y, Bartke A, Turynl D, Miquet JG, Sotelo Al. Mitogenic signaling pathways in the liver of growth hormone (GH)overexpressing mice during the growth period. Cell Cycle. 2016;15:748-59.

68. Al-Regaiey KA, Masternak MM, Bonkowski M, Sun L, Bartke A. Long-lived growth hormone receptor knockout mice: interaction of reduced insulin-like growth factor $\mathrm{i} /$ insulin signaling and caloric restriction. Endocrinology. 2005;146:851-60.

69. Keren A, Tamir Y, Bengal E. The p38 MAPK signaling pathway: a major regulator of skeletal muscle development. Mol Cell Endocrinol. 2006;252:224-30.

70. Harrison BC, Allen DL, Girten B, Stodieck LS, Kostenuik PJ, Bateman TA, Morony S, Lacey D, Leinwand LA. Skeletal muscle adaptations to microgravity exposure in the mouse. J Appl Physiol (1985). 2003:95:2462-70.

71. Bloemberg D, Quadrilatero J. Rapid determination of myosin heavy chain expression in rat, mouse, and human skeletal muscle using multicolor immunofluorescence analysis. PLoS One. 2012;7:e35273.

72. Healy ML, Gibney J, Pentecost C, Croos P, Russell-Jones DL, Sonksen PH, Umpleby AM. Effects of high-dose growth hormone on glucose and glycerol metabolism at rest and during exercise in endurance-trained athletes. J Clin Endocrinol Metab. 2006;91:320-7.

\section{Submit your next manuscript to BioMed Central and we will help you at every step:}

- We accept pre-submission inquiries

- Our selector tool helps you to find the most relevant journal

- We provide round the clock customer support

- Convenient online submission

- Thorough peer review

- Inclusion in PubMed and all major indexing services

- Maximum visibility for your research

Submit your manuscript at www.biomedcentral.com/submit

) Biomed Central 